\title{
Endoscopic and clinicopathological characteristics of colorectal T/NK cell lymphoma
}

\author{
Hideki Ishibashi ${ }^{1}$, Satoshi Nimura ${ }^{2}$, Fumihito Hirai ${ }^{1}$, Naohiko Harada ${ }^{3}$, Hiromi Iwasaki ${ }^{4}$, Sigeto Kawauchi ${ }^{5}$, \\ Yumi Oshiro ${ }^{6}$, Atsuji Matsuyama ${ }^{7}$, Shotaro Nakamura ${ }^{8}$, Yasushi Takamatsu ${ }^{9}$, Hirotoshi Yonemasu ${ }^{10}$, \\ Taturo Shimokama ${ }^{11}$ and Morishige Takeshita ${ }^{2^{*}}$
}

\begin{abstract}
Background: Colorectal T/natural killer (NK)-cell lymphomas (TNKCL) are very rare. Endoscopic and clinicopathological characteristics of colorectal TNKCL have not been clearly demonstrated. In this study, we demonstrated the clinical characteristics of colorectal TNKCL.

Methods: Endoscopic and clinicopathological characteristics were investigated in 27 patients with colorectal monomorphic epitheliotropic intestinal T-cell lymphoma (MEITL), adult T-cell leukemia/lymphoma (ATLL), and other types of TNKCL.

Results: Nine TNKCL patients (33\%) were classified as MEITL, 11 (41\%) as ATLL, and seven (26\%) as other. Four patients with Epstein-Barr Virus-positive (EBV+) TNKCL, two indolent T-cell lymphoproliferative disorder and one anaplastic large cell lymphoma were included in the other group. Endoscopically, six MEITL (67\%) and five ATLL (46\%) showed diffuse-infiltrating type, in which the main endoscopic lesion was edematous mucosa in MEITL, while aphthoid erosion and edematous mucosa were typical in ATLL. Ulcerative type was identified in four other group patients (57\%), including two EBV+ TNKCL. An increase in atypical T-intraepithelial lymphocytes (T-IELs) was noted in seven MEITL (88\%) and six ATLL (60\%) patients, but not in the other group (0\%) patients. Five MEITL patients (56\%) showed features of lymphocytic proctocolitis with increased CD8+ T-IELS.

Conclusions: MEITL and ATLL occasionally invaded the colorectum, and primary involving MEITL was observed. Diffuse infiltrating type was the characteristic endoscopic finding in colorectal MEITL and ATLL, while ulcerative type was observed in the other group. Features of lymphocytic proctocolitis may be prodromal findings of MEITL.
\end{abstract}

Keywords: Colorectum, MEITL, ATLL, T/NK-cell lymphoma, Lymphocytic proctocolitis

\section{Background}

The gastrointestinal (GI) tract is the most involved site of extranodal non-Hodgkin's lymphoma, and the stomach and small intestine are the most affected organs [1, 2]. Primary GI tract lymphomas are mainly composed of

\footnotetext{
* Correspondence: m-take@adm.fukuoka-u.ac.jp

${ }^{2}$ Department of Pathology, Fukuoka University, 7-45-1 Nanakuma, Johnan-ku, Fukuoka, Fukuoka 814-0180, Japan

Full list of author information is available at the end of the article
}

B-cell neoplasia, which involve the whole GI tract, including the colorectum [3]. T/natural killer (NK)-cell lymphoma (TNKCL) of the GI tract has occasionally been reported [4, 5]. Enteropathy-associated T-cell lymphoma (EATL) frequently occurs in Europe and the United States, and consists of CD3+, CD30+/negative, CD56 negative lymphoma cells, which are closely associated with celiac disease [6]. Monomorphic epitheliotropic intestinal T-cell lymphoma (MEITL) mainly shows

(c) The Author(s). 2020 Open Access This article is licensed under a Creative Commons Attribution 4.0 International License, which permits use, sharing, adaptation, distribution and reproduction in any medium or format, as long as you give appropriate credit to the original author(s) and the source, provide a link to the Creative Commons licence, and indicate if changes were made. The images or other third party material in this article are included in the article's Creative Commons licence, unless indicated otherwise in a credit line to the material. If material is not included in the article's Creative Commons licence and your intended use is not permitted by statutory regulation or exceeds the permitted use, you will need to obtain permission directly from the copyright holder. To view a copy of this licence, visit http://creativecommons.org/licenses/by/4.0/ The Creative Commons Public Domain Dedication waiver (http://creativecommons.org/publicdomain/zero/1.0/) applies to the data made available in this article, unless otherwise stated in a credit line to the data. 
medium-sized CD8+, CD56+/negative lymphoma cells, and is more prevalent in East Asia, having no correlation with celiac disease [7]. Intestinal Epstein-Barr viruspositive $(\mathrm{EBV}+)$ TNKCL is mainly reported in East Asia and consists of $\mathrm{CD} 56+/$ negative and $\mathrm{CD} 8+/$ negative lymphoid cells $[8,9]$. Indolent $\mathrm{T}$-cell lymphoproliferative disorder (TLPD) of the GI tract mainly comprises nonepitheliotropic CD4+ small lymphoid cells [10]. EATL, MEITL, EBV+ TNKCL and indolent TLPD mainly involve the small intestine, and colorectal tumor invasion has occasionally been reported [6-12]. Adult T-cell leukemia/lymphoma (ATLL) consists of CD4+ T-cell neoplasm and frequently presents leukemic changes and tumor cell invasion in various organs, including the GI tract [13, 14]. Primary colorectal B-cell lymphoma is found mainly in the ileocecum and endoscopically shows predominantly ulcerative and polypoid types, while diffuse infiltrating type is rare [15]. Small and large intestinal TNKCL including colorectal MEITL and EBV+ TNKCL often presents ulcero-infiltrative, ulcerating, and ulcerofungating type lesions [16]. However, the endoscopic and clinicopathological characteristics of colorectal TNKCL have rarely been reported worldwide $[16,17]$.

The current study reported 27 patients with colorectal TNKCL, with MEITL and ATLL patients accounting for more than two-thirds of the patient population. Detailed endoscopic and clinicopathological characteristics were demonstrated in the TNKCL patients. Furthermore, features of lymphocytic proctocolitis was detected in MEIT $\mathrm{L}$ patients. The relationship between lymphocytic proctocolitis and TNKCL was discussed.

\section{Methods}

\section{Patient selection and clinical findings}

Institutional ethical approval was obtained in compliance with the Declaration of Helsinki (institutional review board approval number: U20-06-006). We retrospectively retrieved records and samples of TNKCL of the GI tract from 106 patients (32 MEITL, 61 ATLL, 13 other types of TNKCL) taken between 1990 and 2018 at the Department of Pathology, Fukuoka University. Histological classification was performed according to the World Health Organization (WHO) classification and reference of intestinal EBV+ TNKCL in 2017 [6-8, 10]. The current study focused on 27 Japanese patients with colorectal TNKCL. Clinical stage was determined according to the Lugano classification [18].

\section{Endoscopic examination}

All 27 patients underwent endoscopic examination of the upper and/or lower GI tract. A video endoscope (Olympus Medical System, Tokyo, Japan) was used for all endoscopic examinations. The endoscopic images or records were reviewed retrospectively by experienced endoscopists (H.I, F.H). Biopsy specimens were taken from the stomach and/or small intestine and/or colon by standard biopsy forceps for histologic examination. Endoscopic findings of the main lesions of colorectal TNKCL were classified into three types based on a previous classification [19]: 1) diffuse infiltrating (colitislike or proctocolitis-like lesion); 2) ulcerative (including stricturing and non-stricturing); and 3) polypoid (localized) (Fig. 1).

\section{Histology and immunohistochemistry}

Histologic examination was performed in biopsy specimens of the GI tract from all 27 TNKCL patients and in colorectal surgical specimens from seven. In addition to the cytohistological characteristics of tumors, two additional histologic findings were examined due to similar features between MEITL and ATLL [20]. Medium-sized and large atypical lymphocytes with irregular nuclei infiltrating the epithelium were defined as atypical intraepithelial lymphocytes (IELs). In benign-looking mucosal layers, more than 20 small IELs per 100 epithelial cells were considered as findings of lymphocytic proctocolitis. For immunohistology, monoclonal and polyclonal antibodies were applied to formalin-fixed tumor samples using a Leica Bond-III automated stainer (Leica Biosystems, Buffalo Grove, IL). Immunostaining of CD3 (PS1; Leica Biosystems, Newcastle, UK), CD4 (4B12; Leica Biosystems), CD8 (C81/44B, Leica Biosystems), CD25 (4C9; Leica Biosystems), CD56 (1B6, Leica), CD30 (BerH2, DakoCytomation, Glostrup, Denmark), CD194 (chemokine receptor (CCR) 4, 1G1; BD Bioscience, San Jose, CA), CD103 (EPR4166²; Abcam, Cambridge, MA), and TIA1 (2GP; Immunotech, Marseille, France) was performed after antigen retrieval. Samples in which more than $30 \%$ of the tumor cells were labeled with a particular antibody marker were classified as positive. Pathological findings were reviewed by two pathologists (S.N and M.T).

\section{Statistical analysis}

Clinicopathological data were analyzed using the chisquared test and Fisher's exact test. A $P$-value of $<0.05$ was considered statistically significant. Overall survival (OS) curves of all examined patients were generated using the Kaplan-Meier method and analyzed by the log-rank test.

\section{Results}

Patient characteristics and treatments

The clinical features of 27 patients with colorectal TNKCL are summarized in Table 1. Nine patients (33\%) were classified as MEITL, 11 (41\%) as ATLL, and seven (26\%) as other (one EBV+ CD56+; three EBV+ CD56 negative TNKCL; two indolent TLPD; one anaplastic 

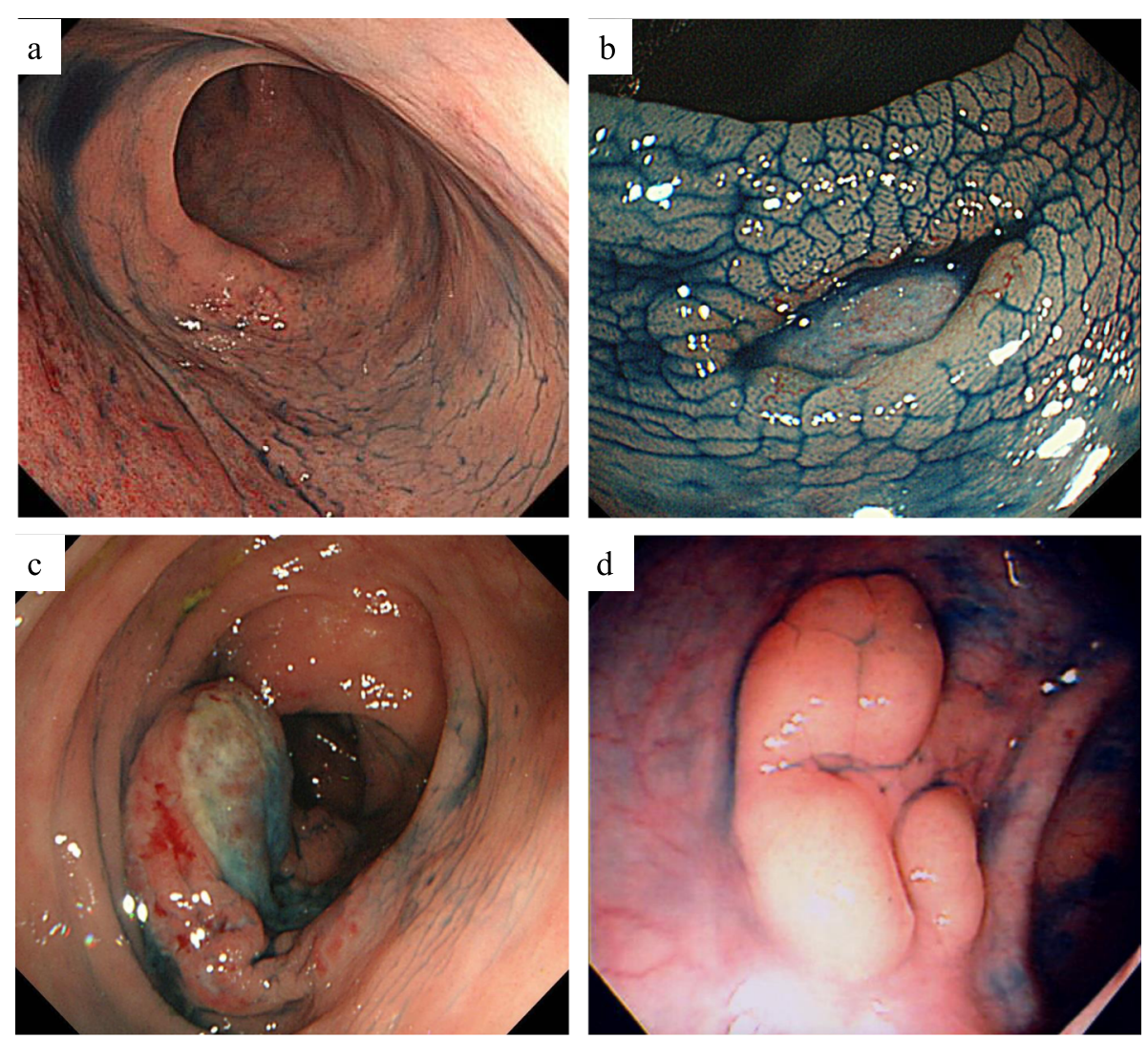

Fig. 1 Endoscopic findings of patients with colorectal TNKCL. Low Gl endoscopic views of the colon showing (a) diffuse infiltrating type MEITL, ulcerative type (b) ATLL and (c) EBV+ CD56 negative TNKCL, and (d) polypoid type ATLL

large cell lymphoma (ALCL)). The median patient age at diagnosis was 60 years (range, $43-84$ years). One patient with MEITL and one with EBV+ CD56+ TNKCL each had a long history of ulcerative colitis (UC) treated with mesalazine, of 13 and 17 years, respectively. The most frequently encountered clinical symptom was chronic diarrhea in five MEITL (56\%) and four ATLL (36\%) patients. The levels of serum lactate dehydrogenase (LDH) and soluble interleukin-2 receptor (sIL-2R) in MEITL patients were significantly lower than those of ATLL patients $(P<0.01)$. Leukemic change was frequently found in six of eight ATLL patients (75\%) compared with two of nine MEITL $(22 \%)(P<0.05)$. Two MEITL patients $(22 \%)$ and two of the other group (EBV+ CD56 negative TNKCL and indolent TLPD) (29\%) were classified as stage I. One MEITL (11\%) and one other group patient (indolent TLPD) (14\%) were classified as stage II1. Six patients were considered as primary colorectal TNKCL without other GI tumor involvement. Four MEITL patients (44\%), 10 ATLL (91\%), and three other group patients (two EBV+ TNKCL and one ALCL) (42\%) were classified as stage IV. Four MEITL (44\%), one ATLL (9\%), and two other group (both EBV+ CD56 negative TNKCL) (29\%) patients underwent colectomy to remove the main tumors. Three MEITL (33\%) and one ATLL (9\%) patients received chemotherapy after surgery. Fourteen patients $(52 \%)$ received combined chemotherapy. Four MEITL and seven ATLL patients received the CHOP regimen (cyclophosphamide, doxorubicin, vincristine, and prednisolone). Three MEITL patients underwent the CHASE (cyclophosphamide, cytarabine, etoposide, and dexamethasone) and SMILE (methotrexate, ifosfamide, etoposide, l-asparaginase, and dexamethasone) regimens. Mogamulizumab was additionally administered to two ATLL patients. Three patients (11\%) received stem cell transplantation after chemotherapy, and three patients (11\%) were not treated.

\section{Involved GI sites and endoscopic findings of colorectal TNKCL}

Involved GI sites and endoscopic findings of the main lesions in 27 colorectal TNKCL patients are summarized in Table 2. Three MEITL (33\%), seven ATLL (64\%), and five other group (four EBV+ TNKCL and one indolent TLPD) (71\%) patients showed colorectal invasion without tumor invasion into the stomach and small intestine. The small intestine and duodenum were the other GIinvolved sites of lymphoma in six MEITL patients, and 
Table 1 Clinical findings and treatments of 27 colorectal T/NK cell lymphoma patients

\begin{tabular}{|c|c|c|c|c|}
\hline Clinical subtype & MEITL & ATLL & Other group & Total \\
\hline No. of cases & $9(33 \%)$ & $11(41 \%)$ & $7(26 \%)$ & 27 \\
\hline Median age (range), y & $63(47-84)$ & $64(50-74)$ & $54(43-69)$ & $60(43-84)$ \\
\hline Male: female & $6: 3$ & $7: 4$ & $6: 1$ & 19:8 \\
\hline Past history of UC & $1(11 \%)$ & 0 & $1(14 \%)$ & $2(7 \%)$ \\
\hline Chronic diarrhea & $5(56 \%)$ & $4(36 \%)$ & $2(29 \%)$ & $11(41 \%)$ \\
\hline Abdominal pain & $4(44 \%)$ & $3(27 \%)$ & $4(57 \%)$ & $11(41 \%)$ \\
\hline Weight loss & $4(44 \%)$ & $2(18 \%)$ & 0 & $6(22 \%)$ \\
\hline Fever & 0 & $2(18 \%)$ & $2(29 \%)$ & $4(15 \%)$ \\
\hline Total protein $(\mathrm{g} / \mathrm{dl})$ & $5.7(4-6.6)$ & $6.3(5.4-7.2)$ & $7.5(5.9-8.4)$ & $6.5(4-8.4)$ \\
\hline Albumin (g/dl) & $3.1(2.1-3.8)$ & $3.4(2.6-4)$ & $3.9(2.7-4.4)$ & $3.5(2.1-4.4)$ \\
\hline $\mathrm{LDH}(\mathrm{U} / \mathrm{l})$ & $191(112-288)^{*}$ & $785(262-2192)^{*}$ & $184(123-244)$ & $387(112-2192)$ \\
\hline $\mathrm{sIL}-2 \mathrm{R}(\mathrm{U} / \mathrm{ml})$ & $1815(587-4410)^{*}$ & $51,643(3501-154,246)^{*}$ & $10,993(1330-25,818)$ & $21,484(587-154,246)$ \\
\hline Leukemic change & $2(22 \%)^{* *}$ & $6 / 8(75 \%)^{* *}$ & $1(14 \%)$ & 9/21 (43\%) \\
\hline Clinical stage I & $2(22 \%)$ & 0 & $2(29 \%)$ & $4(15 \%)$ \\
\hline$\|(\|1\| 2,, \| E)$ & $3(33 \%)$ & $1(9 \%)$ & $2(29 \%)$ & $6(22 \%)$ \\
\hline$\| 1$ & $1(11 \%)$ & 0 & $1(14 \%)$ & $2(7 \%)$ \\
\hline 112 & $1(11 \%)$ & 0 & 0 & $1(4 \%)$ \\
\hline IIE & $1(11 \%)$ & $1(9 \%)$ & $1(14 \%)$ & $3(11 \%)$ \\
\hline IV & $4(44 \%)^{* *}$ & $10(91 \%)^{* *}$ & $3(42 \%)$ & $17(63 \%)$ \\
\hline Surgery & $1(11 \%)$ & 0 & $2(29 \%)$ & $3(11 \%)$ \\
\hline Surgery and chemotherapy & $3(33 \%)$ & $1(9 \%)$ & 0 & $4(15 \%)$ \\
\hline Chemotherapy & $2(22 \%)^{* *}$ & $9(82 \%)^{* *}$ & $3(42 \%)$ & $14(52 \%)$ \\
\hline Chemotherapy and SCT & $2(22 \%)$ & $1(9 \%)$ & 0 & $3(11 \%)$ \\
\hline No treatment & $1(11 \%)$ & 0 & $2(29 \%)$ & $3(11 \%)$ \\
\hline
\end{tabular}

${ }^{*} P<0.01 ;{ }^{* *} P<0.05$; UC Ulcerative colitis; $L D H$ Lactate dehydrogenase; sIL-2R Soluble interleukin-2 receptor

$\mathrm{SCT}$, stem cell transplantation

the small intestine, duodenum, and stomach were the involved sites of four ATLL. Endoscopically, six MEITL (67\%), five ATLL (46\%), and two other group (EBV+ CD56+ TNKCL and indolent TLPD) (29\%) patients showed diffuse infiltrating type lesions, among which four MEITL patients showed edematous mucosa (Fig. 2a, b), and three and two ATLL patients showed mainly aphthoid erosion (Fig. 2c, d) and edematous mucosa (Fig. 2e, f), respectively. Four patients of the other group (two EBV+ CD56 negative TNKCL, one indolent TLPD and one ALCL) (57\%), one MEITL (11\%), and three ATLL (27\%) patients showed ulcerative type lesions. Two MEITL (22\%) and three ATLL (27\%) patients showed polypoid type lesions. Seven MEITL patients (78\%), seven ATLL (64\%), and one other group (EBV+ CD56+ TNKCL, 14\%) showed more than two colorectal lesions by lymphoma cells. Four MEITL patients (44\%), five ATLL (46\%), and one of the other group (EBV+ CD56+ TNKCL, 14\%) showed multiple invasions by lymphoma cells from the cecum to the rectum.

\section{Pathological and immunohistological findings of} colorectal TNKCL

The pathological and immunohistological findings of 27 colorectal TNKCL patients are summarized in Table 3. Histologically, all nine MEITL patients (100\%) had monomorphic medium-sized cell lymphoma, while eight ATLL patients (73\%) had pleomorphic medium-sized cell lymphoma. In the other group, one EBV+ CD56+ TNKCL and two indolent TLPD (42\%) were composed of pleomorphic medium-sized cell lymphoma, and three EBV+ CD56 negative TNKCL and one ALCL (57\%) showed monomorphic large cell lymphoma. Seven of eight MEITL patients (88\%) and six of 10 ATLL (60\%) showed an increase in atypical IELs in the overlying epithelium and in glands in and near the tumors. These findings were not observed in other group patients $(0 \%)$. Five MEITL patients (56\%) showed features of lymphocytic proctocolitis, in which an increase in reactive small IELs was found in the background nonneoplastic mucosa (Fig. 3a, b), and one ATLL (9\%) showed an increase 
Table 2 Involved gastrointestinal sites and endoscopic findings in 27 colorectal T/NK cell lymphoma patients

\begin{tabular}{|c|c|c|c|c|}
\hline & MEITL $(n=9)$ & ATLL $(n=11)$ & Other group $(n=7)$ & Total $(n=27)$ \\
\hline \multicolumn{5}{|l|}{ Gastrointestinal sites } \\
\hline Colon & $3(33 \%)$ & $7(64 \%)$ & $5(71 \%)$ & $15(56 \%)$ \\
\hline Colon+other & $6(67 \%)$ & $4(36 \%)$ & $2(29 \%)$ & $12(44 \%)$ \\
\hline Colon+small intestine & $2(22 \%)$ & $1(9 \%)$ & 0 & $3(11 \%)$ \\
\hline Colon+small intestine+duodenum & $4(44 \%)$ & 0 & 0 & $4(15 \%)$ \\
\hline Colon+duodenum+stomach & 0 & $2(18 \%)$ & $1(14 \%)$ & $3(11 \%)$ \\
\hline Colon+stomach & 0 & $1(9 \%)$ & $1(14 \%)$ & $2(7 \%)$ \\
\hline \multicolumn{5}{|l|}{ Endoscopic findings } \\
\hline Diffuse-infiltrating & $6(67 \%)$ & $5(46 \%)$ & $2(29 \%)$ & $13(48 \%)$ \\
\hline Ulcerative & $1(11 \%)$ & $3(27 \%)$ & $4(57 \%)$ & $8(30 \%)$ \\
\hline Polypoid & $2(22 \%)$ & $3(27 \%)$ & $1(14 \%)$ & $6(22 \%)$ \\
\hline \multicolumn{5}{|l|}{ Involved colon sites } \\
\hline $\mathrm{C} / \mathrm{A} / \mathrm{T} / \mathrm{D} / \mathrm{S} / \mathrm{R}$ & $5 / 6 / 5 / 4 / 6 / 6$ & $6 / 7 / 8 / 6 / 6 / 6$ & $1 / 4 / 2 / 1 / 2 / 2$ & $12 / 17 / 15 / 11 / 14 / 14$ \\
\hline Localized lesion & $2(22 \%)$ & $4(36 \%)$ & $6(86 \%)$ & $12(44 \%)$ \\
\hline Multiple lesions & $7(78 \%)$ & $7(64 \%)$ & $1(14 \%)$ & $15(56 \%)$ \\
\hline Two lesions & $3(33 \%)$ & $1(9 \%)$ & 0 & $4(15 \%)$ \\
\hline Three lesions $(T+D+R)$ & 0 & $1(9 \%)$ & 0 & $1(4 \%)$ \\
\hline Six lesions $(C+A+T+D+S+R)$ & $4(44 \%)$ & $5(46 \%)$ & $1(14 \%)$ & $10(37 \%)$ \\
\hline
\end{tabular}

C Cecum; A Ascending colon; $T$ Transverse colon; $D$ Descending colon; $S$ Sigmoid colon; $R$ Rectum
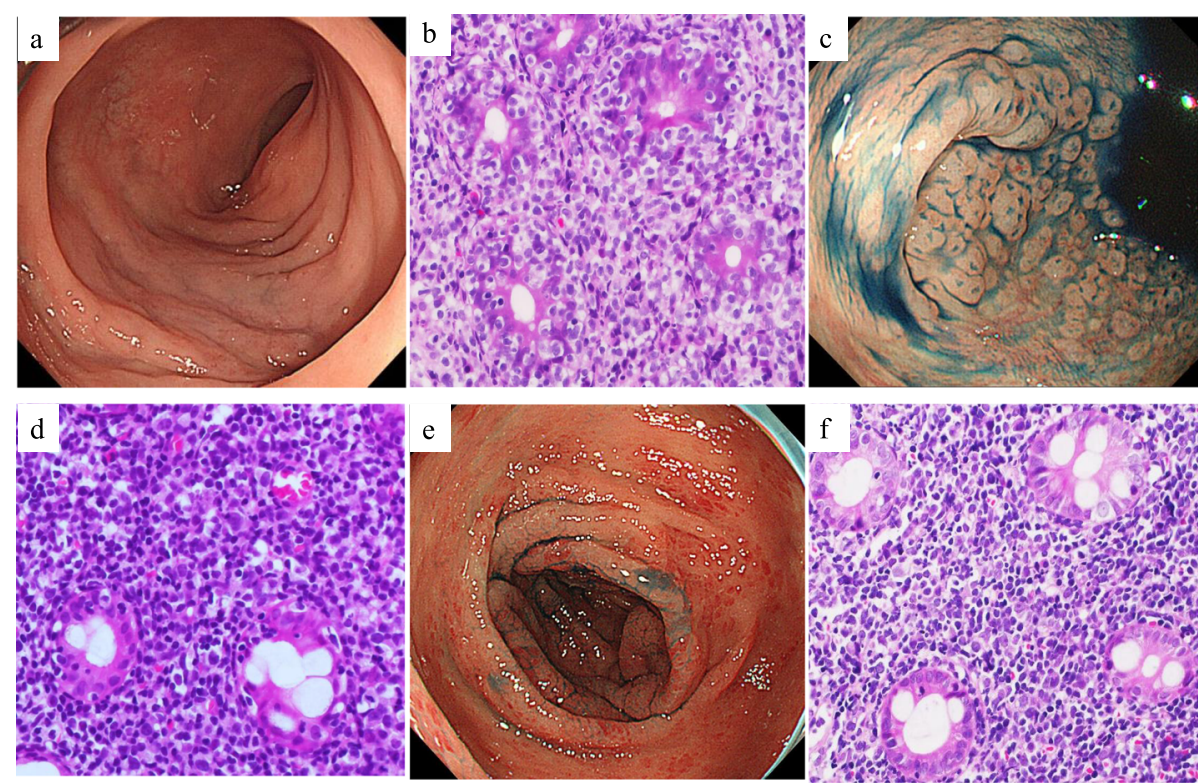

Fig. 2 Endoscopic and histologic findings of diffusely infiltrating type MEITL (a, b) and ATLL (c-f). a Endoscopic view of sigmoid colon showing mild edematous mucosa with small erosion. $\mathbf{b}$ Histological analysis showing small nests of atypical intraepithelial lymphocytes (IELs), preserved glands, and invasion by medium-sized atypical lymphocytes (hematoxylin and eosin stain, $\times 400$ ). c Endoscopic view of cecum showing many aphthoid colitis-like lesions. d Histological analysis showing preserved glands, small nests of atypical IELs, and invasion by pleomorphic mediumsized atypical lymphocytes, $\times 400$. e Endoscopic view of the descending colon showing reddish, mildly edematous mucosa. $\mathbf{f}$ Histological analysis showing invasion by small and medium-sized atypical lymphocytes, $\times 400$ 
Table 3 Pathological and immunohistological findings of 27 colorectal T/NK cell lymphoma patients

\begin{tabular}{|c|c|c|c|c|}
\hline & MEITL $(n=9)$ & ATLL $(n=11)$ & Other group $(n=7)$ & Total $(n=27)$ \\
\hline \multicolumn{5}{|l|}{ Histological findings } \\
\hline Monomorphic medium-sized cell & $9(100 \%)^{*}$ & $1(9 \%)^{*}$ & $0(0 \%)$ & $10(37 \%)$ \\
\hline Pleomorphic medium-sized cell & $0(0 \%)^{*}$ & $8(73 \%)^{*}$ & $3(42 \%)$ & $11(41 \%)$ \\
\hline Monomorphic large cell & $0(0 \%)$ & $0(0 \%)$ & $4(57 \%)$ & $4(15 \%)$ \\
\hline Pleomorphic large cell & $0(0 \%)$ & $2(18 \%)$ & $0(0 \%)$ & $2(7 \%)$ \\
\hline Increased atypical IELs in tumors & $7 / 8(88 \%)$ & $6 / 10(60 \%)$ & $0 / 5(0 \%)$ & $13 / 23(57 \%)$ \\
\hline Lymphocytic proctocolitis & $5(56 \%)^{* *}$ & $1(9 \%)^{* *}$ & $0(0 \%)$ & $6(22 \%)$ \\
\hline \multicolumn{5}{|l|}{ Tumor cell markers } \\
\hline CD3 & $9(100 \%)$ & $11(100 \%)$ & $5(71 \%)$ & $25(93 \%)$ \\
\hline CD4 & $1(11 \%)^{*}$ & $9(82 \%)^{*}$ & $3(42 \%)$ & $13(48 \%)$ \\
\hline CD8 & $9(100 \%)^{*}$ & $2(18 \%)^{*}$ & $2(29 \%)$ & $13(48 \%)$ \\
\hline CD25 & $0 / 8(0 \%)^{*}$ & $11(100 \%)^{*}$ & $2 / 6(33 \%)$ & $13 / 25(52 \%)$ \\
\hline CD56 & $8(89 \%)^{*}$ & $1(9 \%)^{*}$ & $1(14 \%)$ & $10(37 \%)$ \\
\hline CD30 & 0/8 (0\%) & 2/9 (22\%) & $4(57 \%)$ & $6 / 24(25 \%)$ \\
\hline CD194 (CCR4) & $0 / 7(0 \%)^{*}$ & $9 / 9(100 \%)^{*}$ & $0(0 \%)$ & 9/23 (39\%) \\
\hline CD103 & $6(67 \%)$ & $4(36 \%)$ & $1(14 \%)$ & 11 (41\%) \\
\hline TIA-1 & $9(100 \%)^{*}$ & $0 / 8(0 \%)^{*}$ & $6(86 \%)$ & 15/24 (63\%) \\
\hline EBERs & $0(0 \%)$ & $0(0 \%)$ & $4(57 \%)$ & $4(15 \%)$ \\
\hline
\end{tabular}

${ }^{*} P<0.01 ;{ }^{* *} P<0.05$; IELs Intraepithelial lymphocytes

in reactive small IELs. Immunohistologically, lymphoma cells in all nine MEITL patients were CD3+, CD8+, and TIA-1+, and eight (89\%) were CD56+. Atypical and reactive IELs were CD3+, CD8+, TIA-1+, and CD103+/-. Lymphoma cells in all 11 ATLL patients were CD3+, CD25+, and of those, nine (100\%) were CD194+ (CCR4) and nine (82\%) were CD4+. Six MEITL patients (67\%), four ATLL (36\%), and one other group patient (14\%) showed CD103+ lymphoma cells. No EBERs+ tumor cells were found in MEITL and ATLL patients. In the other group, one patient showed nasal type EBV+
CD56+ TNKCL, and a further three had EBV + CD56 negative and $\mathrm{CD} 8+/$ negative lymphoma. Two indolent TLPD patients demonstrated CD4+ T-cells in the tumor, and one ALCL patient had CD30+, CD4+ and TIA1+ tumor cells.

\section{Analysis of patient prognosis}

The $50 \%$ OS of nine MEITL patients was 9.5 months, that of 11 ATLL was 9 months, and that of five other group patients was over 240 months. There was no prognostic difference in OS between MEITL and ATLL
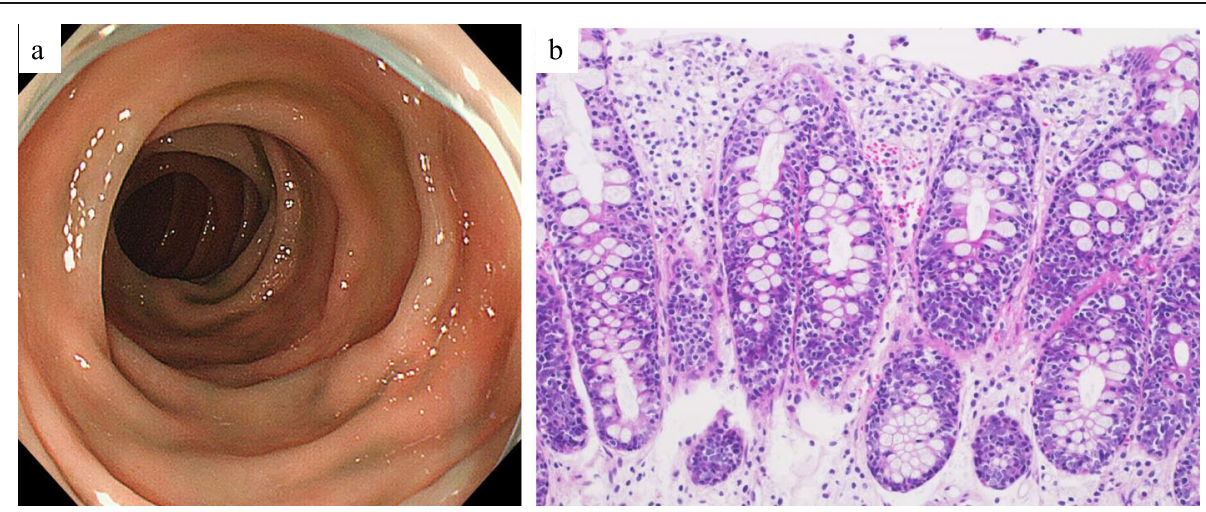

Fig. 3 Lower Gl endoscopic and histologic findings of features of lymphocytic colitis in MEITL. a Endoscopic view of the descending colon showing mild edematous mucosa. $\mathbf{b}$ Histological analysis showing many scattered small IELs and no overt stromal invasion by lymphoma cells (hematoxylin and eosin stain, $\times 200$ ) 
patients (Fig. 4a). The $50 \%$ OS of the five patients (three MEITL, one EBV+ CD56 negative TNKCL and one indolent TLPD) in the early stages (I and II1) was more than 240 months. The $50 \%$ OS of 20 patients in the advanced stages (II2, IIE and IV) was 8.5 months. There was no significant difference between the early and advanced stages $(P=0.063)$ (Fig. 4b).

\section{Discussion}

Previous studies have shown that endoscopically, eight of 15 MEITL lesions (53.3\%) and eight of $10 \mathrm{EBV+}$ TNKCL (80\%) showed the ulcero-infiltrative type in 42 GI TNKCL [16]. Infiltrating and superficial/erosive type lesions were rarely found in each of the above histological groups. Another study demonstrated that nine intestinal EBV+ CD56+/negative TNKCL patients showed ulcerative $(n=5)$ and protruding $(n=4)$ type lesions [8]. Furthermore, 34 of $47 \mathrm{EBV}+\mathrm{CD} 56+$ TNKCL patients (72.3\%) frequently showed multiple ulcerative lesions [21]. In the current study, the ulcerative type was frequently encountered in four of seven other group patients (57\%), in which two EBV+ CD56 negative TNKCL were included. Six MEITL patients (67\%) and five ATLL (46\%) mainly showed the diffuse infiltrating type. Although ulcerating and polypoid type lesions were also found in resting MEITL and ATLL patients, the diffuse infiltrating type was a frequently encountered characteristic of colorectal MEITL and ATLL, which was different from that of EBV+ TNKCL as well as B-cell lymphoma $[3,8,16,21]$. Further detailed studies are necessary to clarify the endoscopic difference among MEITL, ATLL and $\mathrm{EBV}+\mathrm{TNKCL}$.

Small intestinal MEITL mostly showed intramucosal spreading of lymphoma cells with neoplastic CD103+ and CD8+ T-IELs [11]. It was reported that lymphoma cells in 21 of 31MEITL (68\%) as well as 31 of 56 GI ATLL patients (55\%) showed expression of CD103 homing receptor of T-IELs, and ATLL had similar histopathological characteristics to MEITL with respect to increased atypical and reactive T-IELs [20]. The endoscopic findings of MEITL have been reported as edematous mucosa with mosaic and diffuse mucosal thickening patterns, and shallow ulceration, as well as ulcerative type tumors in the small intestine [22]. The endoscopic findings of GI-involved acute type ATLL showed superficial spreading-type lesions (equal to the diffuse infiltrating type) in 12 of 23 lesions (52\%) [23]. In the current study, more than two colorectal lymphomatous lesions were frequently found in MEITL (78\%) and ATLL (64\%) patients. Histologically, increased atypical T-IELs were found in MEITL (88\%) and ATLL (60\%) patients. Although MEITL and GI ATLL showed distinct disease entities, the endoscopic and pathological characteristics of colorectal MEITL were similar to those of ATLL.

A multicenter study from the Asia Lymphoma Study Group identified 38 MEITL patients, and the involved sites were the small intestine and stomach (5\%), small intestine (63\%), small and large intestine (16\%), and large intestine (18\%) [11]. MEITL can discontinuously expand into the mucosa along the entire GI tract. Aoyama et al. reported a primary colonic MEITL patient with Lugano clinical stage I, having mucosal edema and multiple ulcers in the transverse, splenic flexure, and sigmoid colon [24]. The current study also demonstrated that three MEITL patients (33\%) had primarily presenting colorectal lesions. Endoscopically, six MEITL patients (67\%) showed diffuse infiltrating type with more than two lymphomatous lesions in the whole colorectum. A previous study reported two colonic MEITL patients with clinicopathological features that mimicked those of ulcerative colitis and lymphocytic colitis, and the latter had a history of 'lymphocytic colitis' 6 months before [25]. Although collagenous sprue, microscopic (lymphocytic and collagenous) colitis, and celiac disease show distinct clinical entities, these diseases reveal similar features of
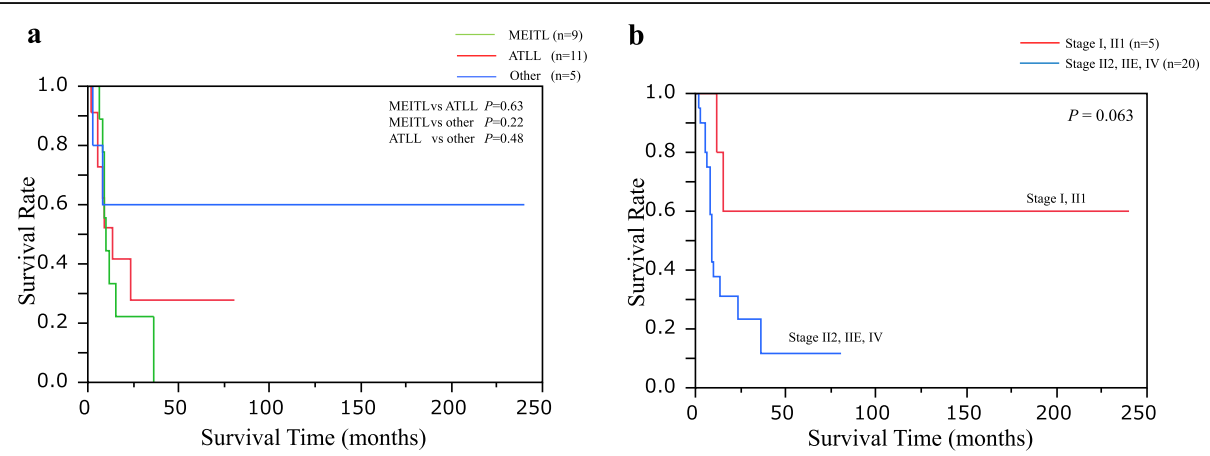

Fig. 4 Overall survival (OS) curves in 25 patients with colorectal TNKCL. a 50\% OS rates of MEITL, ATLL and other group were 9.5 months, 9 months, and more than 240 months, respectively. There was no statistical difference between MEITL and ATLL. b The 50\% OS of five patients with primary colorectal TNKCL in early stages (I or II1) was over 240 months, and that of 20 patients in advanced stages was 8.5 months. There was no statistical difference between the two groups $(P=0.063)$ 
colitis with an increase in T-IELs [26, 27]. Five examined MEITL patients (56\%) had features of lymphocytic proctocolitis with reactive small T-IELs, and the findings were almost similar to lymphocytic colitis, in which more than 20 IELs per 100 epithelial cells and no or few distorted crypts were detected [28]. The features of lymphocytic proctocolitis may be characteristic of background mucosa in colorectal and other GI MEITL. Cumulative studies are necessary to clarify the relationship between lymphocytic proctocolitis and MEITL.

The prognosis of GI TNKCL patients is worse, and 1and 3-year OS rates were 57 and $26 \%$, respectively, in 42 intestinal MEITL patients [29]. Among them, OS of MEIT L patients with Lugano clinical stages I, II1, and II2 was 18.8 months, which was significantly better than 4.9 months in stages IIE and IV $(P=0.01)$. The Lugano stage as well as the performance scales were important prognostic factors. Clinical stages in 55 GI EBV+ TNKCL patients and 61 GI-involved ATLL were also indicated as a significant prognostic factor $(P<0.001$ and $P=0.017$, respectively) $[9,23]$. In the current study, only six of 27 colorectal TNKCL patients $(22 \%)$ were found with stage I and II1 disease, and the $50 \%$ OS of the five was more than 240 months. The major symptom of examined colorectal TNKCL patients was chronic diarrhea. Thus, the clinical symptoms as well as the features of lymphocytic proctocolitis with CD8+ T-IELs may be important in detecting the early stages of colorectal TNKCL.

\section{Conclusions}

MEITL, ATLL and other types of TNKCL occasionally involved the colorectal regions, and primary and concurrently involved colorectal MEITL was recognized. The endoscopic and clinicopathological characteristics of colorectal MEITL and ATLL revealed diffuse infiltrating lesions with increased atypical $\mathrm{T}$ IELs. However, features of lymphocytic proctocolitis in the background mucosa were characteristic of colorectal MEITL. Primary colorectal MEITL patients in the early clinical stages were rarely identified and showed a rather prolonged clinical course. It is important to recognize endoscopic and clinicopathological characteristics including features of lymphocytic proctocolitis to detect early-stage colorectal TNKCL.

\footnotetext{
Abbreviations

Gl: Gastrointestinal; TNKCL: T/natural killer-cell lymphomas;

EATL: Enteropathy-associated T-cell lymphoma; MEITL: Monomorphic epitheliotropic intestinal T-cell lymphoma; EBV: Epstein-barr virus; TLPD: T-cell lymphoproliferative disorder; ATLL: Adult T-cell leukemia/lymphoma; WHO: World health organization; IELs: Intraepithelial lymphocytes; OS: Overall survival; ALCL: Anaplastic large cell lymphoma; UC: Ulcerative colitis; LDH: Lactate dehydrogenase; sIL-2R: Soluble interleukin-2 receptor
}

\section{Acknowledgements}

We thank H. Nikki March, PhD, from Edanz Group (www.edanzediting.com/ ac) for editing a draft of this manuscript.

\section{Authors' contributions}

H.I. and M.T. designed the research. S.N., F.H., N.H., H.I., S.K., Y.O., A.M., S.N., Y.T., H.Y., T.S. performed research. H.I. and M.T. performed statistical analysis. H.I. and M.T. wrote the paper. H. I. and M. T. read and appproved the final manuscript.

\section{Funding}

This study received no financial support.

\section{Availability of data and materials}

The datasets used and analyzed in the current study are available from the corresponding author on reasonable request.

\section{Ethics approval and consent to participate}

All procedures performed in studies involving human participants were in accordance with the ethical standards of the Institutional Ethics Committee of Fukuoka University and with the 1964 Helsinki Declaration and its later amendments or comparable ethical standards. The study protocol was approved by the Institute Research Committee and Institute Ethics Committee Fukuoka University (IRB number. U20-06-006).

Consent for publication

Not applicable.

\section{Competing interests}

The author declare that they have no competing interests.

\section{Author details}

'Department of Gastroenterology and Medicine, Faculty of Medicine, Fukuoka University, 7-45-1 Nanakuma, Johnan-ku, Fukuoka, Fukuoka 814-0180, Japan. ${ }^{2}$ Department of Pathology, Fukuoka University, 7-45-1 Nanakuma, Johnan-ku, Fukuoka, Fukuoka 814-0180, Japan. ${ }^{3}$ Department of Gastroenterology National Hospital Organization, Kyushu Medical Center, 1-8-1 Jigyohama, Chuo-ku, Fukuoka, Fukuoka 810-8563, Japan. ${ }^{4}$ Department of Hematology National Hospital Organization, Kyushu Medical Center, 1-8-1 Jigyohama, Chuo-ku, Fukuoka, Fukuoka 810-8563, Japan. ${ }^{5}$ Department of Pathology, National Hospital Organization, Kyushu Medical Center, 1-8-1 Jigyohama, Chuo-ku, Fukuoka, Fukuoka 810-8563, Japan. 'Division of Pathology, Matsuyama Red Cross Hospital, 1 Bunkyocho, Matsuyama, Ehime 790-8524, Japan. ${ }^{7}$ Department of Pathology and Oncology, School of Medicine, University of Occupational and Environmental Health, 1-1 Yahatanishi-ku, Kitakyushu, Fukuoka 807-8555, Japan. ${ }^{8}$ Division of Gastroenterology, Iwate Medical University, 2-1-1 Shiwa-gun, Morioka, Iwate 020-8505, Japan. ${ }^{9}$ Division of Medical Oncology, Hematology and Infectious Diseases, Faculty of Medicine, Fukuoka University, 7-45-1 Nanakuma, Johnan-ku, Fukuoka, Fukuoka 814-0180, Japan. ${ }^{10}$ Department of Pathology, Oita Red Cross Hospital, 3-2-37 Chiyomachi Oita, Oita 870-0033, Japan.

${ }^{11}$ Department of Pathology, Steel Memorial Yahata Hospital, 1-1-1

Yahatahigashi-ku, Kitakyushu, Fukuoka 805-8508, Japan.

Received: 20 July 2020 Accepted: 5 October 2020

Published online: 21 October 2020

References

1. Groves FD, Linet MS, Travis LB, et al. Cancer surveillance series: nonHodgkin's lymphoma incidence by histologic subtype in the United States from 1978 through 1995. J Natl Cancer Inst. 2000;92:1240-51.

2. Shi Z, Ding H, Shen QW, et al. The clinical manifestation, survival outcome and predictive prognostic factors of 137 patients with primary gastrointestinal lymphoma (PGIL): Strobe compliant. Medicine (Baltimore). 2018;97:e9583.

3. Nakamura S, Matsumoto T, lida M, et al. Primary gastrointestinal lymphoma in Japan: a clinicopathologic analysis of 455 patients with special reference to its time trends. Cancer. 2003;97:2462-73.

4. van Vliet C, Spagnolo DV. T-and NK-cell lymphoproliferative disorders of the gastrointestinal tract: review and update. Pathology. 2020;52:128-41. 
5. Chuang SS, Chang ST, Chuang WY, et al. NK-cell lineage predicts poor survival in primary intestinal NK-cell and T-cell lymphomas. Am J Surg Pathol. 2009;33: 1230-40.

6. Bhagat G, Jaffe ES, Chott A, et al. Enteropathy-associated T-cell lymphoma in WHO Classification of Tumors of Haematopoietic and Lymphoid Tissues, (eds SH Swerdlow, E Campo, NL Harris et al.) France: LARC Press, Lyon; 2017. p. 372-377.

7. Jaffe ES, Chott A, Ott G, et al. In: Swerdlow SH, Campo E, Harris NL, et al., editors. Monomorphic epitheliotropic intestinal T-cell lymphoma in WHO Classification of Tumors of Haematopoietic and Lymphoid Tissues. France: LARC Press, Lyon; 2017. p. 377-8.

8. Hu LM, Takata K, Miyata-Takata T, et al. Clinicopathological analysis of 12 patients with Epstein-Barr virus-positive primary intestinal T/ natural killer-cell lymphoma (EBV ${ }^{+}$ITNKL). Histopathology. 2017;70: 1052-63.

9. $\quad \mathrm{Yu}$ B-H, Shui R-H, Shueng W-Q, et al. Primary intestinal extranodal natural killer/T-cell lymphoma, nasal type: a comprehensive clinicopathological analysis of 55 cases. PLoS One. 2016;11:e0161831.

10. Jaffe ES, Chott A, Ott G, et al. In: Swerdlow SH, Campo E, Harris NL, et al., editors. Indolent T-cell lymphoproliferative disorder of the gastrointestinal tract in WHO Classification of Tumors of Haematopoietic and Lymphoid Tissues. France: LARC Press, Lyon; 2017. p. 379-80.

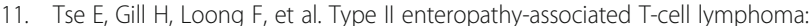
a multicenter analysis from the Asia lymphoma study group. Am J Hematol. 2012;87:663-8

12. Ishibashi H, Nimura S, Kayashima $Y$, et al. Multiple lesions of gastrointestinal tract invasion by monomorphic epitheliotropic intestinal T-cell lymphoma, accompanied by duodenal and intestinal enteropathylike lesions and microscopic lymphocytic proctocolitis: a case series. Diag Pathol. 2016;11:66.

13. Ohshima K, Jaffe ES, Yoshino T, et al. In: Swerdlow SH, Campo E, Harris $\mathrm{NL}$, et al., editors. Adult T-cell leukemia/lymphoma, in WHO Classification of Tumors of Haematopoietic and Lymphoid Tissues. France: LARC Press, Lyon; 2017. p. 363-7.

14. Uchiyama T, Ishikawa T, Imura A. Adhesion properties of adult T cell leukemia cells. Leuk Lymphoma. 1995;16:407-12

15. Hori Y, Yamamoto H, Nozaki Y, et al. Colorectal diffuse large B-cell lymphoma: molecular subclassification and prognostic significance of immunoglobulin gene translocation. Hum Pathol. 2020;96:67-78.

16. Kim DH, Lee D, Kim JW, et al. Endoscopic and clinical analysis of primary Tcell lymphoma of the gastrointestinal tract according to pathological subtype. J Gastroenterol Hepatol. 2014;29:934-43.

17. Wang MH, Wong JM, Lien HC, et al. Colonoscopic manifestations of primary colorectal lymphoma. Endoscopy. 2001;33:605-9.

18. Rohatiner A, d' Amore F, Coiffier B, et al. Report on a workshop convened to discuss the pathological and standing classification of gastrointestinal tract lymphoma. Ann Oncol. 1994;5:397-400.

19. Nakamura S, Matsumoto T, Takeshita M, et al. A clinicopathologic study of primary small intestine lymphoma: prognostic significance of mucosa-associated lymphoid tissue-derived lymphoma. Cancer. 2000;88: 286-94.

20. Ishibashi H, Nimura S, Ishitsuka K, et al. High expression of intestinal homing receptor CD103 in adult T-cell leukemia/lymphoma, similar to 2 other CD8+ T-cell lymphomas. Am J Surg Pathol. 2016;40:462-70.

21. Jiang $M$, Chen $X$, Zhang $X$, et al. Prognostic characteristics of gastrointestinal tract NK/T-cell lymphoma: an analysis of 47 patients in China. J Clin Gastroenterol. 2013;47:e74-9.

22. Hong YS, Woo YS, Park G, et al. Endoscopic findings of enteropathyassociated T-cell lymphoma type II: a case series. Gut Liver. 2016;10:147-51.

23. Ishibashi H, Nimura S, Kayashima Y, et al. Endoscopic and clinicopathological characteristics of gastrointestinal adult T-cell leukemia/ lymphoma. J Gastrointest Oncol. 2019;10:723-33.

24. Aoyama Y, Tsunemine H, Zushi Y, et al. Colonal monomorphic epitheliotropic intestinal T-cell lymphoma with novel phenotype of cytoplasmic CD3 expression. J Clin Exp Hematop. 2018;58:102-6.

25. Tian S, Xiao SY, Chen Q, et al. Monomorphic epitheliotropic intestinal T-cell lymphoma may mimic intestinal inflammatory disorders. Int J Immunopathol Pharmacol. 2019;33:2058738419829387.

26. Lan N, Shen B, Yuan L, et al. Comparison of clinical features, treatment, and outcomes of collagenous sprue, celiac disease, and collagenous colitis. J Gastroenterol Hepatol. 2017;32:120-7.
27. Sonnenberg A, Turner KO, Genta RM. Associations of microscopic colitis with other lymphocytic disorders of the gastrointestinal tract. Clin Gastroenterol Hepatol. 2018;16:1762-7.

28. Langner C, Aust D, Ensari A, et al. Histology of microscopic colitis-review with a practical approach for pathologists. Histopathol. 2015;66:613-26.

29. Yi JH, Lee GW, Jung HR, et al. Multicenter retrospective analysis of the clinicopathologic features of monomorphic epitheliotropic intestinal T-cell lymphoma. Ann Hematol. 2019;98:2541-50.

\section{Publisher's Note}

Springer Nature remains neutral with regard to jurisdictional claims in published maps and institutional affiliations.
Ready to submit your research? Choose BMC and benefit from:

- fast, convenient online submission

- thorough peer review by experienced researchers in your field

- rapid publication on acceptance

- support for research data, including large and complex data types

- gold Open Access which fosters wider collaboration and increased citations

- maximum visibility for your research: over $100 \mathrm{M}$ website views per year

At BMC, research is always in progress.

Learn more biomedcentral.com/submissions 